SOLID STATE

\section{Electroluminescent Devices}

\section{from a Correspondent}

IN twenty years the transistor has almost ousted the simple electronic vacuum tube and a similar usurpation may be facing the cathode ray tube. Although such a development would take at least twenty years, devices for producing the visual effect are becoming commercially interesting, in particular the electroluminescent (EL) lamp which is making an impact as a simple indicating device. A smooth transition is in progress from a first stage in which a reasonably efficient, convenient, reliable and cheap solid state visible light source is being produced, to a second stage where modest display requirements will be fulfilled by combining an array of EL lamps with fully integrated memory and addressing circuitry. It should then be possible to decide whether to continue towards a solid state display which will match and even surpass the cathode ray tube. With such grand plans, it is not surprising that the symposium on electroluminescent solid state devices arranged by the Institute of Physics and the Physical Society and the Institute of Electrical Engineers attracted 250 delegates to London on March 4.

Discussing gallium arsenide phosphide alloys, Dr C. E. E. Stewart (Standard Telephone Laboratories, Harlow) showed that not only II-VI materials have native defects, while Dr G. Lidgard (Plessey, Towcester) showed how the scanning electron microscope can be used for optimizing the combination of good minority carrier injection with efficient luminescence in gallium phosphide.

The wisdom of the almost total commitment of world effort to the light emitting diode rather than the clectroluminescent panel is questionable, as $\mathrm{Mr} \mathrm{A}$. Vecht (Woolwich Polytechnic) showed when he summarized recent advances by his group working on zinc sulphide d.c. EL panels. Greater light output at $100 \mathrm{~V}$ d.c., a green alternative to the usual orangeyellow and no loss in brightness at constant input power during 500 hours of testing, emphasized the seriousness of the challenge. But it is becoming increasingly important to understand these devices sufficiently to decide whether the present poor half-life at constant voltage is curable, or whether it represents a fundamental limitation. Dr R. L. Rouse (GEC, Wembley) showed that such an understanding has not yet been reached when discussing the voltage dependence of $\mathrm{ZnS}$ d.c. EL panels.

The gallium arsenide infrared lamp coated with an up-converting phosphor is an interesting recent development. Dr W. A. Shand (Signals Research and Development Establishment, Christchurch) talked about the optimization of these phosphors. But the highlight of the day was a review of possible new tetrahedrally bonded materials for electroluminescence by Dr C. Hilsum (Royal Radar Establishment, Malvern). $\mathrm{He}$ thought that gallium nitride showed the greatest promise.

Practical problems of optimization and addressing were considered by Dr C. Gooch (Services Electronics Research Laboratory, Baldock), who felt that the immediate future depended on the commercial success with gallium phosphide and gallium arsenide phosphide lamps. The problem of integration of EL devices with silicon circuitry has been approached rather unusually by Dr J. Morant (University of Durham). He has found a phosphor (willemite) which is epitaxially compatible with silicon and is now hoping to make it efficiently electroluminescent.

\section{POLLUTION \\ Teach-in at Edinburgh}

\section{from a Correspondent}

ON March 6, Edinburgh University was the venue for a teach-in at which scientists, economists, moral philosophers, politicians and representatives of industry discussed pollution with students and the public. This probably indicates a significant change in attitudes towards pollution since ten years ago, say, when reports of the effects of certain types of pollution were just reaching the public. The mood of the meeting was therefore one of "what are we going to do about it, when and how?" It was good to see polluters and polluted facing up to one another on the same panel, so that the audience, consisting of some cight hundred people, was able to hear both sides of the problem.

Professor Alan Williams (University of York) pointed out that economics concerns things people value, and that a general achievement of a sense of values is difficult. For example, the cost of saving a few lives which might otherwise be lost due to a polluted water supply could be diverted to building a hospital to save many lives. It is dangerous, too, to take decisions on existing costs; in the end, what value will posterity place on action taken now ? Certainly, Canon Hugh Montefiore (University Church, Cambridge) felt that it was our moral duty to leave the Earth as we found it.

Some members of parliament were a little naive in their approach and alarmingly unaware of the inefficiency of some of the existing pollution legislation. Mr David Steele (MP for Roxburgh, Selkirk and Pecbles), however, pointed out that it had taken general disasters to bring in certain legislation on pollution, and we must not wait for another disaster before doing anything further. Dr John Dunwoody (Parliamentary Under-Secretary, Ministry of Health and Social Security) agreed with this point, and felt that it was no use waiting for agreements on international control before action was taken. We must impose national controls, he said. The present position concerning the restriction of DDT indicates that this idea is shared by other nations.

One thing is certain, as Mr Roland Glover (Scottish Marine Biological Association), represcnting the Natural Environment Research Council, stressed. "It is no longer sensible to try to study ecology without considering man and society as significant components of the natural system. It will be necessary to improve and develop the environmental sciences as a whole so that our understanding of nature will be sufficient for us to diagnose and predict all the problems, of which pollution is but one, that are created by the changing pattern of society. The detection and measurement of the effects of pollution in the field will always be difficult, and often impossible, without a thorough understanding of the baselines of natural variation." 